\title{
Treatment after ACL injury: Panther Symposium ACL Treatment Consensus Group
}

\author{
Theresa Anita Diermeier 다, ${ }^{1}$ Ben B Rothrauff, ${ }^{2}$ Lars Engebretsen, ${ }^{3}$ Andrew Lynch, ${ }^{4}$

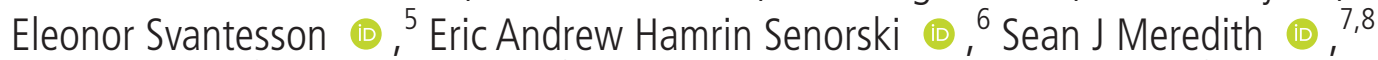 \\ Thomas Rauer, ${ }^{9}$ Olufemi R Ayeni, ${ }^{10}$ Mark Paterno, ${ }^{11}$ John W Xerogeanes, ${ }^{12}$ \\ Freddie $\mathrm{H} \mathrm{Fu}_{1}{ }^{7}$ Jon Karlsson, ${ }^{13}$ Volker Musahl, ${ }^{7}$ the Panther Symposium ACL Treatment \\ Consensus Group
}

For numbered affiliations see end of article.

\section{Correspondence to} Dr Theresa Anita Diermeier, Department of Sportorthopedics, Klinikum rechts der Isar der Technischen Universitat Munchen, Munchen 81675, Germany;

resi.diermeier@gmx.de

This article has been copublished in the British Journal of Sports Medicine, Knee Surgery, Sports Traumatology, Arthoscopy, Journal of ISAKOS and the Orthopaedic Journal of Sports Medicine.

Accepted 28 April 2020

Published Online First

13 July 2020

Check for updates

(C) Author(s) (or their employer(s)) 2021. No commercial re-use. See rights and permissions. Published by BMJ.

To cite: Diermeier TA, Rothrauff BB, Engebretsen $L$, et al. Br J Sports Med 2021;55:14-22.

\section{ABSTRACT}

Treatment strategies for ACL injuries continue to evolve. Evidence supporting best practice guidelines to manage $A C L$ injury is largely based on studies with low-level evidence. An international consensus group of experts was convened determine consensus regarding best available evidence on operative versus non-operative treatment for $A C L$ injury. The purpose of this study is to report the consensus statements on operative versus non-operative treatment of $\mathrm{ACL}$ injuries developed at the $\mathrm{ACL}$ Consensus Meeting Panther Symposium 2019. Sixty-six international experts on the management of $A C L$ injuries, representing 18 countries, convened and participated in a process based on the Delphi method of achieving consensus. Proposed consensus statements were drafted by the Scientific Organising Committee and Session Chairs. Panel participants reviewed preliminary statements prior to the meeting and provided initial agreement and comments on the statement via online survey. During the meeting, discussion and debate occurred for each statement, after which a final vote was then held. Eighty per cent agreement was defined a priori as consensus. A total of 11 of 13 statements on operative versus non-operative treatment of $\mathrm{ACL}$ injury reached consensus during the Symposium. Nine statements achieved unanimous support, two reached strong consensus, one did not achieve consensus, and one was removed due to redundancy in the information provided. In highly active patients engaged in jumping, cutting and pivoting sports, early anatomical $\mathrm{ACL}$ reconstruction is recommended due to the high risk of secondary meniscus and cartilage injuries with delayed surgery, although a period of progressive rehabilitation to resolve impairments and improve neuromuscular function is recommended. For patients who seek to return to straight plane activities, non-operative treatment with structured, progressive rehabilitation is an acceptable treatment option. However, with persistent functional instability, or when episodes of giving way occur, anatomical $\mathrm{ACL}$ reconstruction is indicated. The consensus statements derived from international leaders in the field may assist clinicians in deciding between operative and non-operative treatment with patients after an ACL injury. Level of evidence: Level V

\section{INTRODUCTION}

ACL injuries are one of the most common injuries of the knee, with an incidence of approximately 85 per 100000 in patients aged between 16 years and 39 years. ${ }^{1-3}$ The ACL is the primary stabiliser of the knee limiting anterior tibial translation and internal rotation, with deficiency resulting in anterior and rotatory instability. ${ }^{4}$ The most common mode of injury is a non-contact mechanism during pivoting, cutting and jumping with the knee slightly flexed and in a valgus position. ${ }^{67}$

Both operative and non-operative treatments of an ACL injury continue to evolve. ${ }^{8-11}$ Improved understanding of the structure and function of the native ACL has supported the development and adoption of anatomical ACL reconstruction techniques. ${ }^{3}$ In parallel, increased recognition of the resilience of the neuromuscular system in achieving dynamic, functional knee stability despite ACL deficiency has concurrently supported non-operative treatment as a viable strategy in some patients. ${ }^{12} 13$

Successful outcomes following both operative and non-operative treatment necessitate progressive rehabilitation, which entails staged and phase-adjusted physical therapy with the aim to address impairments, achieve functional stability and to safely return to sport. ${ }^{14}$ The acute phase after the injury or surgery focuses on the elimination of residual symptoms (effusion, pain) and impairments (range of motion, quadriceps activation and strength). Subsequently, neuromuscular and perturbation training are implemented to improve knee stabilisation. ${ }^{15} 16$ The last phase aims to further optimise muscular strength, return to preinjury sports level through sport-specific exercises and assess psychological readiness for the return to sport. ${ }^{17}$ Any discussion of non-operative treatment within this consensus document implies the completion of a progressive, staged rehabilitation protocol.

Discussions of operative treatment within this consensus document implies anatomical ACL reconstruction (table 1), intended to restore the ACL to its native dimensions, collagen orientation and insertion sites. ${ }^{18}$ Anatomical ACL reconstruction includes both single-bundle and double-bundle techniques, followed by a progressive rehabilitation programme that considers the natural healing cascade and ligamentisation of the graft. ${ }^{19}$ Following fixation during ACL reconstruction, a biological graft transitions from a tendon to a structure with ultrastructural, biochemical and mechanical properties more similar to the native ACL. ${ }^{20}$ These properties of the graft depend on the phase of ligamentisation, with the minimum graft strength occurring postoperatively between 4 weeks and 12 weeks. ${ }^{19}{ }^{20}$ Comprehensive 


\begin{tabular}{ll}
\hline $\begin{array}{l}\text { Table } 1 \\
\text { 'evidence to support the interpretation and use of the anatomic ACL }\end{array}$ \\
reconstruction checklist ${ }^{\text {' }}$ An
\end{tabular}

rehabilitation after operative ACL reconstruction is also paramount for clinical outcome and return to sports.

Whereas operative treatment aims to reduce laxity, nonoperative treatment aims to reduce functional instability and both thereby prevent further damage to the menisci and cartilage, which may contribute to post-traumatic osteoarthritis (PTOA). ${ }^{2122}$ Functional bracing, intended to reduce the risk of ACL injury by decreasing peak ligament strain, has not yet been conclusively shown to achieve this goal, as the evidence is still limited. ${ }^{23} 24$

The patients' characteristics that determine who should undergo immediate surgery and which patients may be successfully treated non-operatively are uncertain. Three different patient responses after ACL injury have been described: (1) A coper can return to the preinjury level without surgery and subjective instability. (2) An adapter reduces his/her level of activity to avoid subjective instability. (3) A non-coper cannot return to preinjury activity level due to subjective instability and episodes of giving way. ${ }^{25} \mathrm{~A}$ screening tool to differentiate potential copers from non-copers was developed and included a combination of hop tests, questionnaires on general knee function and the frequency of giving-way episodes. ${ }^{2627}$ Patients categorised as potential copers thereafter participated in structured progressive rehabilitation with additional perturbation training. ${ }^{15}{ }^{16}$ Regardless of this three response concept, there is a strong historical view that the treatment approach should be determined through a shared decision-making process between the patient and the provider. ${ }^{28}$ In particular, the physician should share information on the evidence-based treatment options while also considering the patient's expectations and goals. While the patient and provider are the primary stakeholders in the shared decisionmaking process, the potential influence of secondary stakeholders, such as family and coaches, should be anticipated so as to minimise interests potentially conflicting with the health of the patient.

Taken as a whole, the current body of evidence regarding the treatment of ACL injury is mostly based on low level of evidence. Therefore, an international, multidisciplinary group of experts was assembled to develop expert-based and evidence-based consensus statements to assist clinicians in managing this difficult pathology. The purpose of this article is to report the results of the consensus group addressing the best available evidence on operative versus non-operative treatment of ACL injury that were developed at the 2019 Panther Symposium ACL consensus meeting.

\section{MATERIALS AND METHODS}

An international and multidisciplinary group of experts of ACL injury chosen from the leadership of international organisations (American Orthopaedic Society for Sports Medicine (AOSSM), European Society for Sports Traumatology, Knee Surgery and Arthroscopy (ESSKA) and International Society of Arthroscopy, Knee Surgery and Orthopaedic Sports Medicine (ISAKOS)), including orthopaedic surgeons (15), sports medicine physicians (2), physical therapists (5) and scientists (1), convened in a 1 -year consensus-building effort, which culminated in the cconsensus meeting, at the University of Pittsburgh, Pennsylvania, USA (figure 1). The symposium included experts from 18 countries, spanning six continents. Experts were assigned to one, or more, of the three consensus groups defined by a specific subtopic within ACL injury. The operative versus non-operative treatment consensus group consisted of 34 participants. A modified Delphi method was used to develop the consensus statements.

The scientific organising committee and session chairs proposed a series of statements on the basis of a literature review. These were drafted with the aim of addressing areas of current controversy within the treatment of ACL injury, intended to assist clinicians in the management of this injury. Prior to the meeting, the proposed statements were presented to the panellists via a web-based survey. Each panellist indicated the extent of agreement or disagreement with each statement, and was asked to provide comments on each statement. On the third day of the 2019 Panther Symposium, after 2 days of presentations by symposium delegates on current knowledge, a consensus discussion was held.

A total of 13 statements on the operative versus non-operative treatment of ACL injury were discussed. The session was moderated by two experts (LE and ADL). Initial results and comments from the web-based survey were presented for each statement followed by discussion, debate and revision by the working group. Consensus was determined by show of hands. Satisfactory consensus was defined as $80 \%$ agreement. Opposing views were documented and discussed. Statements with less than $80 \%$ agreement were included in the consensus paper, noting the percentage of agreement. Statements felt to be irrelevant or redundant were excluded from this final paper.

This consensus group was assigned two liaisons (TD and BBR) who were responsible for amending each statement as requested over the course of the discussion. Liaisons transcribed the discussion, and subsequently completed a literature review of MEDLINE for each finalised statement. To reduce the potential for bias in the data analysis and/or literature review, liaisons did not submit answers to the online questionnaire, nor did they partake in the voting process.

\section{RESULTS}

Of the 13 statements discussed by this working group, 9 achieved unanimous consensus, 2 achieved non-unanimous consensus, $1 \mathrm{did}$ not achieve consensus and 1 was excluded due to redundancy in the information provided (table 2). The 12 finalised statements, with supporting literature, are as follows.

Operative and non-operative treatments are both acceptable treatment options for $\mathrm{ACL}$ injury.

Agree $23 / 23,100 \%$

After ACL injury some patients are able to regain good functional knee stability following non-operative treatment entailing progressive rehabilitation and are able to return to preinjury sports activity level without an ACL reconstruction (copers), ${ }^{29} 30$ 


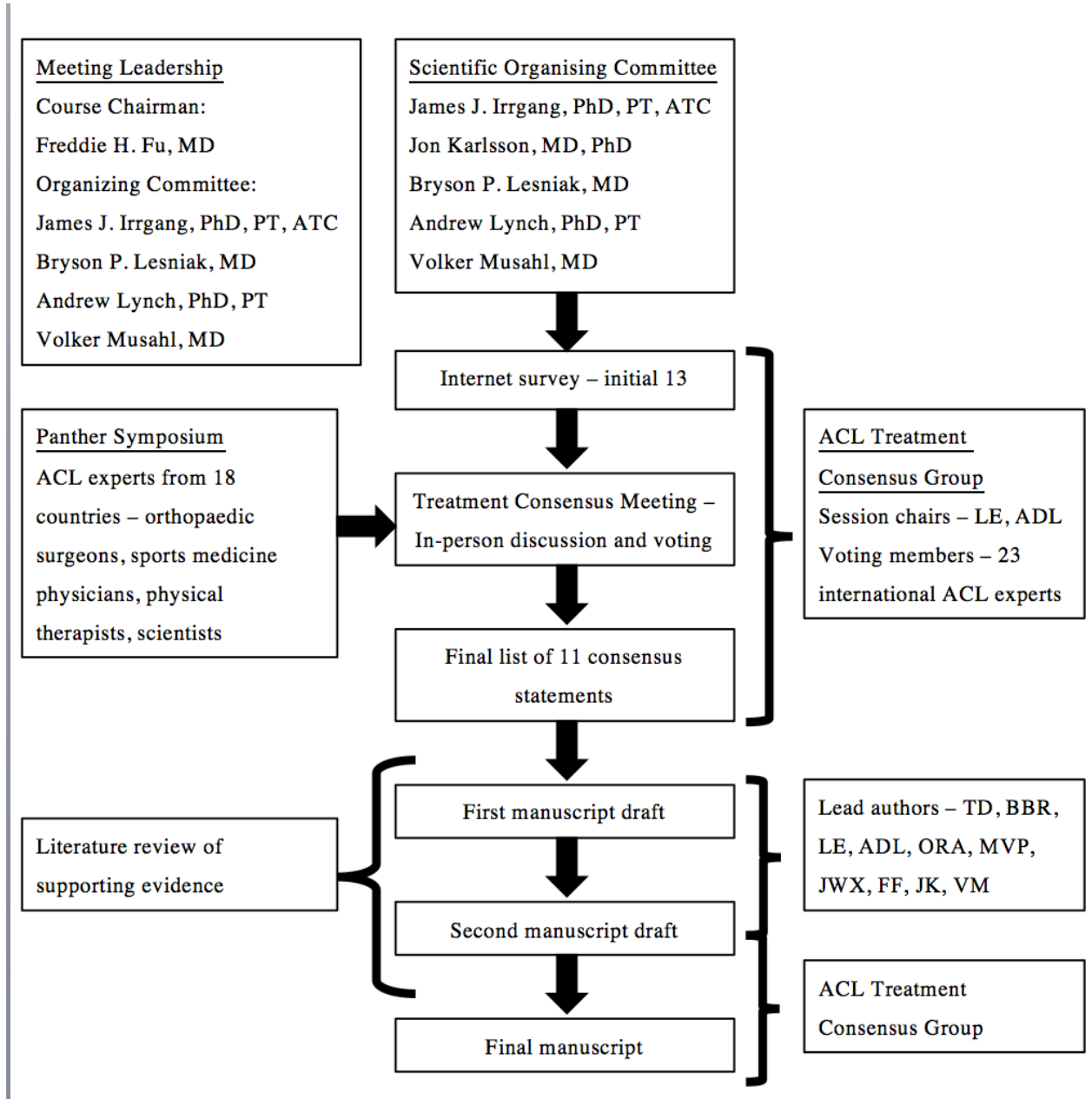

Figure 1 ACL consensus meeting Panther Symposium 2019. ATC, certified athletic trainer; PT, physical therapist.

Table 2 Consensus statements on non-operative and operative treatment of ACL injury

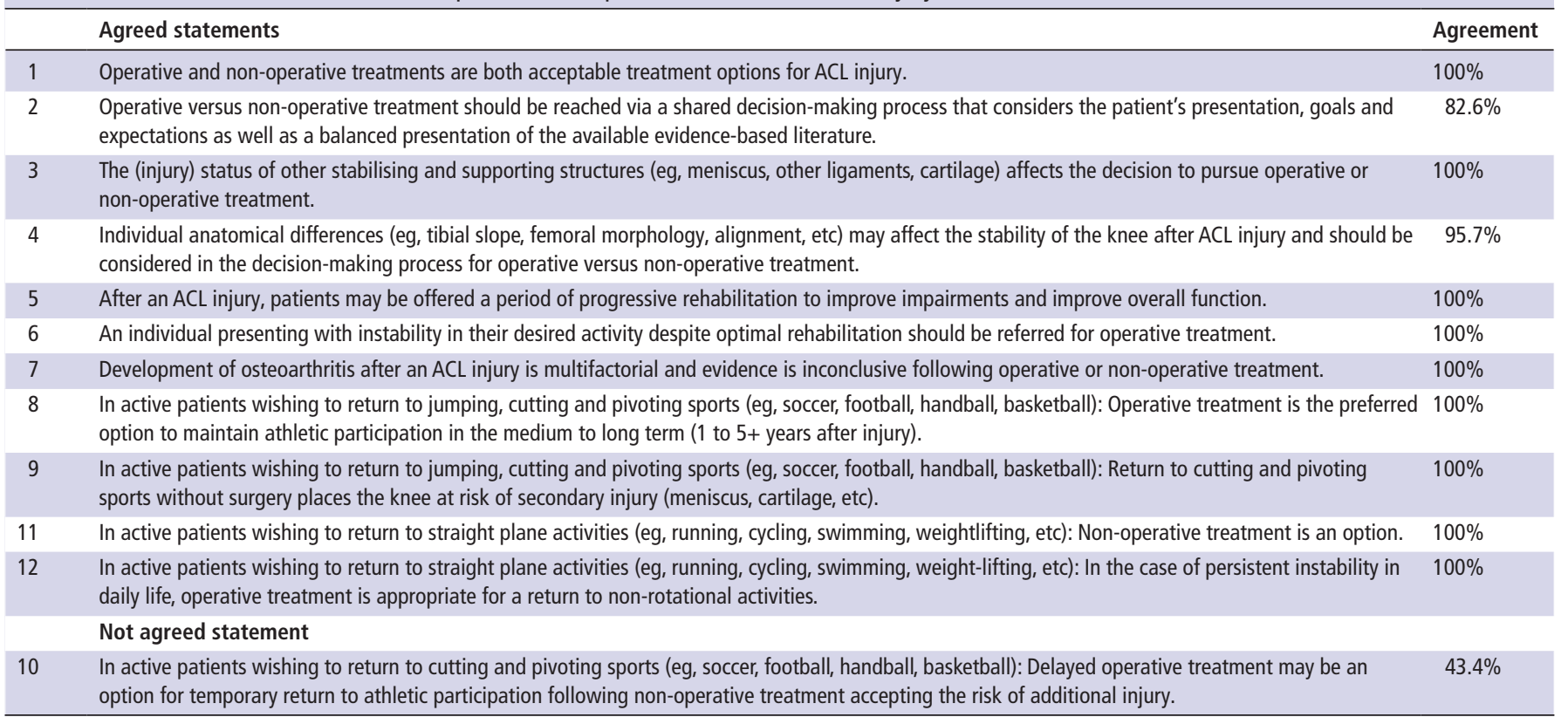


but the identification of these patients has been challenging. ${ }^{31}$ In a prospective study the combination of hop tests, muscle strength, subjective instability (episodes of giving way) and knee function was found to be a moderate predictive tool for identification of potential copers. ${ }^{10} 262730$ A randomised controlled trial comparing operative and non-operative treatment in 121 young active, non-elite patients with isolated ACL tears demonstrated no superiority of either treatment with regard to patientreported outcomes at 2-year and 5-year follow-ups. ${ }^{89}$ However, almost $40 \%$ of the patients who were initially assigned to the non-operative treatment group required delayed ACL reconstruction and 32\% of the patients (29 menisci in 19 patients) had subsequent surgery for meniscal pathology during the 2-year follow-up period. In contrast, 34 patients (56\%) who underwent early ACL reconstruction also had meniscus treatment (24 partial resection, 10 fixation) simultaneously with the ACL reconstruction, but only 10\% (6 meniscal injuries in 5 patients) in the operatively treated group had meniscal injuries that required surgical treatment during follow-up. ${ }^{8}$ With regard to knee laxity, as measured by KT-1000 and pivot shift test, non-operative treatment resulted in a larger anterior tibial translation $(9.0 \mathrm{~mm}$ vs $6.6 \mathrm{~mm})$ and higher rate of rotatory laxity (positive pivot shift test: $78 \%$ vs $25 \%$ ). A matched-paired study based on the Swedish National ACL registry comparing operative and non-operative treatment after ACL injury reported superior results for quality of life, knee function and symptoms at 1-year, 2-year and 5-year follow-ups for ACL reconstruction compared with non-operative treatment. ${ }^{32}$ Another prospective trial with highly active patients included 832 patients at baseline with subacute ACL tear, whereas 345 patients were initially screened for possibility of non-operative treatment. Based on the results of various hop tests, subjective instability and general knee function, 146 patients were classified as potential copers at final follow-up after 10 years, and only 25 patients had not undergone ACL reconstruction. ${ }^{10}$

Conclusion: Operative and non-operative are both acceptable treatment options after ACL injury and a decision based on concomitant injuries, risk factors, level of activity and patient's expectations and goals is recommended as demonstrated in the following statements.

Operative versus non-operative treatment should be reached via a shared decision-making process that considers the patient's presentation, goals and expectations as well as a balanced presentation of the available evidence-based literature. Agree 19/23, 82.6\%

Before a particular treatment approach is pursued, the provider (physician and/or physical therapist) should present the evidence for operative and non-operative treatment options for an ACL injury to the patient. Based on the patient's activity level, goals and expectations, a decision should be made with the patient (and parents/guardians for minors) and provider as the primary stakeholders. ${ }^{28}$ Physicians and physical therapists must be aware that personal and situational factors such as level of competition, time in season, playing status and role in the team, could affect the injured athletes' treatment decision. Parents and coaches are often the first individuals from whom athletes seek support or advise. ${ }^{33}$ However, the coach may be conflicted by the interests of the team and the athlete's immediate and future health. ${ }^{34} 35$ For some athletes, reactions and comments of parents related to the athlete's injury were reported to negatively affect the athletes treatment decision, with pressure to return to sport. ${ }^{33}$ Due to the possible conflict of interest, secondary stakeholders such as family, coaches and agents, among others, should not be directly involved in the decision-making process, although their indirect involvement may be considered.

Conclusion: Shared decision-making of the treatment option should be based on the evidence for operative and non-operative treatment, patient's expectations and goals with the provider and patient as the primary stakeholders.

The (injury) status of other stabilising and supporting structures (eg, meniscus, other ligaments, cartilage) affects the decision to pursue operative or non-operative treatment.

Agree $23 / 23,100 \%$

ACL injuries often occur together with concomitant injury to other knee structures, with meniscal injuries reported in $23 \%-42 \%$, cartilage lesions in $27 \%$, and combined meniscal and chondral lesions in $15 \%$ of cases (figure 2). ${ }^{32} 3637$

However, most studies investigating non-operative ACL treatment or studies comparing non-operative and operative treatments are limited to isolated ACL tears. ${ }^{8-10}$ Based on clinical and biomechanical studies, an ACL reconstruction with concomitant meniscus repair may restore knee kinematics and results in improved patient-reported outcomes at short-term and long-term follow-up. ${ }^{38-41}$ In contrast, simultaneously performed meniscectomy with ACL reconstruction is associated with poorer clinical outcome, inferior knee kinematics and a high rate (48\%-100\%) of osteoarthritis in the long-term follow-up. ${ }^{42-46}$ In case of delayed ACL reconstruction, a meniscectomy is more often performed than a meniscus repair. ${ }^{47}$ The presence of concomitant knee injuries should therefore always be considered in the decision-making process, given the worse outcomes for meniscus injuries with delayed ACL reconstruction and higher rate of osteoarthritis in the long-term follow-up. In case of concomitant meniscus injury repair, anatomical ACL reconstruction with additional treatment of the meniscus injury is recommended.

In case of multiple ligament injuries involving the ACL and at least one other ligament, the literature has consistently demonstrated that operative management is superior to nonoperative management. ${ }^{48-50}$ Based on a recent systematic review, early (within 3 weeks after injury) reconstruction in a multiple ligament-injured knee was superior to delayed reconstruction with regard to clinical outcome measurements (Lysholm Score, 90 vs 82 out of 100 points) and resulted in higher rate of excellent/good International Knee Documentation Committee (IKDC) Scores (47\% vs 31\%). ${ }^{49}$ Although failure after ligament

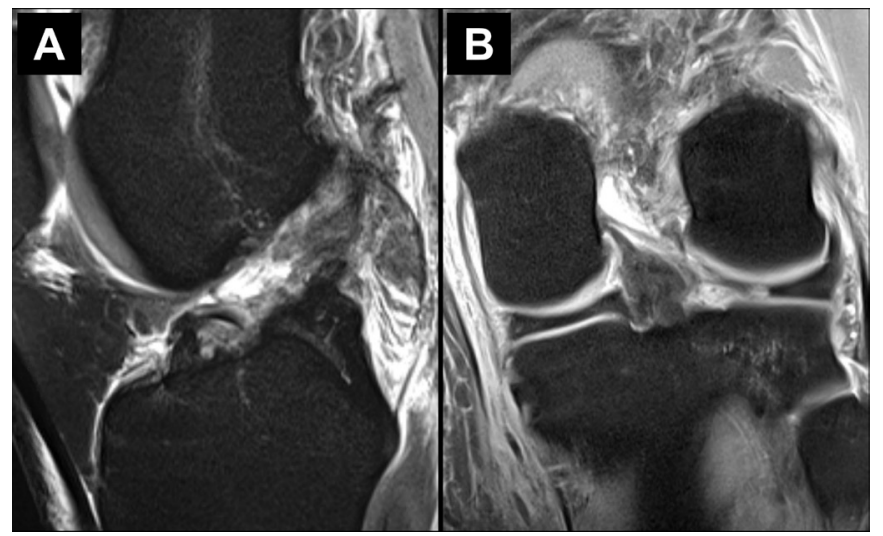

Figure 2 As seen in T2 MRI sequences, the patient sustained a (A) complete $A C L$ rupture and $(B)$ associated lateral meniscus root tear. 
reconstruction is not consistently defined in the literature (ie, the need for revision vs objective laxity vs rerupture on imaging vs Knee Injury and Osteoarthritis Outcome Score (KOOS) <44) the failure rate in a multiple ligament-injured knee is lower for reconstruction (6\%-9\%) compared with repair techniques (37\%-40\%). ${ }^{1151}$

Conclusion: The presence of a repairable meniscal lesion or a multiple ligament injury is an indication for an early anatomical ACL reconstruction with concomitant treatment of the other injured structures (meniscus repair, ligament repair/ augmentation).

Individual anatomical differences (eg, tibial slope, femoral morphology, alignment, etc) may affect the stability of the knee after ACL injury and should be considered in the decision-making process for operative versus non-operative treatment.

Agree $22 / 23,95.7 \%$

Bony morphology and soft tissue injury patterns have been demonstrated to influence knee joint laxity. An increased posterior tibial slope is associated with increased anterior tibial translation, as well as with increased rotatory instability (figure 3). ${ }^{52}$ In addition, an increased lateral femoral condyle ratio resulted in increased rotatory instability. ${ }^{5455}$ Severe varus limb alignment $\left(>5^{\circ}\right)$ was demonstrated to increase the risk for more rapid degeneration of the medial compartment in the ACLdeficient knee, and is also a risk factor for secondary failure after an ACL reconstruction. ${ }^{5657}$ Whereas lateral meniscus tears and a complete lateral meniscectomy result in increased rotatory instability, ${ }^{59} 59$ a complete medial meniscectomy more strongly affects anterior tibial translation. However, general joint laxity (Beighton Hypermobility Score $>4$ ) is not associated with increased rotatory laxity in the ACL-deficient knee. ${ }^{60}$

Conclusion: Bony morphology features (increased posterior tibial slope, severe varus limb alignment, etc) and concomitant injuries associated with increased or persistent knee instability should be considered in the decision-making process and are a relative indication for operative treatment.

After an ACL injury, patients may be offered a period of progressive rehabilitation to improve impairments and overall function.

Agree 23/23, 100\%

Knee joint effusion, limited range of motion, and decreased quadriceps strength in the injured leg are common impairments initially after an ACL injury. ${ }^{61} 62$ Effusion can limit quadriceps function and in turn affect knee joint mechanics. ${ }^{63}$ Progressive rehabilitation is useful in treating these initial impairments. ${ }^{10}$
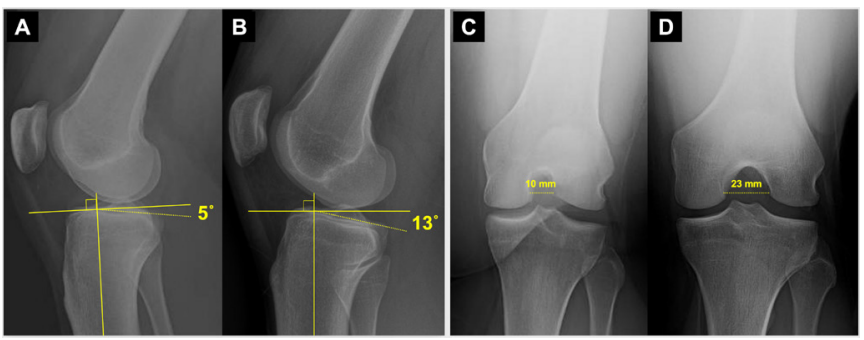

Figure 3 (A-B) Posterior tibial slope varies among patients, with greater slope increasing the risk of failure following $A C L$ reconstruction. (C-D) Notch dimensions vary among patients, with small Notch width dimensions constituting a relative contraindication for double-bundle anterior cruciate ligament reconstruction (ACLR).
In patients with the possibility for non-operative treatment (absence of concomitant meniscus injuries, or multiligament injuries requiring surgical treatment) before the evaluation of knee instability a phase of rehabilitation is recommended to treat the initial impairments. Afterwards, evaluation by hop tests, assessment of strength, overall knee function and subjective instability is recommended to quantify the patients' potential for non-operative treatment. If progressive rehabilitation does not provide a satisfactory outcome, then operative intervention needs to be pursued and the progressive rehabilitation will have enhanced the postsurgical outcome. ${ }^{64}$ In a cohort study with 2187 patients after resolution of impairments, one group was treated with neuromuscular training (ie, strengthening and neuromuscular training) before ACL reconstruction and was compared with immediate ACL reconstruction. At the 2-year follow-up, preoperative progressive rehabilitation before ACL reconstruction resulted in better patient-reported outcome (KOOS and IKDC), compared with ACL reconstruction without preoperative rehabilitation. ${ }^{64}$ Whereas $63 \%$ of the patients without preoperative rehabilitation returned to sport at the 2-year follow-up, which is similar to the reported rate $(65 \%)$ in a meta-analysis from 2016 , the rate increased to $72 \%$ in the group that completed preoperative rehabilitation. ${ }^{64}$

Conclusion: Preoperative resolution of impairments and a period of rehabilitation is recommended for operative and nonoperative treatment.

An individual presenting with instability in their desired activity despite optimal rehabilitation should be referred for operative treatment.

Agree $23 / 23,100 \%$

Persistent instability is a risk factor for further damage to the meniscus and cartilage. ${ }^{65}$ Although the definitions of recurrent instability and episodes of instability vary in current literature, a correlation between persistent and recurrent instability after ACL injury and meniscus and cartilage lesions has been demonstrated in several studies. ${ }^{66-68}$ In a cohort study of 62 patients with acute ACL reconstructions, 37 with subacute ACL reconstructions and 36 with chronic ACL reconstructions, one episode of giving way was associated with a threefold higher odds for lateral meniscus tears. Timing of surgery and episodes of instability influenced the incidence of lateral meniscus tears with 1.45 higher odds in subacute (6-12 weeks) ACL reconstruction and 2.82 higher odds in chronic (>12 weeks) ACL reconstruction. ${ }^{67}$ Moreover, frequent episodes of instability are correlated with medial meniscus tears and chondral injuries. ${ }^{68}$ Chondral defects and meniscectomy have been demonstrated as predictive factors for the development of osteoarthritis after ACL reconstruction. ${ }^{6970}$

A partial ACL injury progressed to a complete ACL tear in $39 \%$ of young active patients treated non-operatively, with half of the complete tears presenting with a concomitant meniscal lesion at the time of reconstruction. Age $\leq 20$ years and participation in pivoting contact sports were identified as significant risk factors for progression to a complete tear. ${ }^{71}$

Conclusion: If patient-reported instability or severe episodes of giving way occur during the progressive rehabilitation, patients should be referred for anatomical ACL reconstruction.

Development of osteoarthritis after an $\mathrm{ACL}$ injury is multifactorial and evidence is inconclusive following operative or nonoperative treatment Agree 23/23, $100 \%$ 
Osteoarthritis is the most common joint disease, affecting the cartilage, and all other tissues of the joint as well. ${ }^{72}$ The pathomechanism of PTOA has not been fully elucidated, but based on current research, the process of development of osteoarthritis is multifactorial. ${ }^{72}$ Injuries, like ACL ruptures, can affect the joint biomechanics and cause chondral and meniscal lesions, and thereby reduce the sustainability of the joint. Matrix metalloproteases are responsible for cartilage destruction and synovial inflammation, and have been shown to be elevated following ACL injury and reconstruction. ${ }^{73} 74 \mathrm{~A}$ meta-analysis of 24 observational studies found a fourfold increased risk for PTOA after knee injuries, although the definition of an injury was largely heterogeneous among the analysed studies. ${ }^{75}$ After ACL injury the prevalence of PTOA is increased after both operative and non-operative treatments as compared with those without injury. ${ }^{22}{ }^{76-78}$ Based on a recent systematic review with 41 included studies, the rate of OA after ACL reconstruction varied between $1 \%$ and $80 \%$, with meniscectomy as the consistent risk factor for the development of OA. ${ }^{79}$ Although longterm outcome studies after ACL reconstruction are available, the technique has evolved in recent years, with a shift from nonanatomical ACL reconstruction to anatomical ACL reconstruction, limiting conclusions on the possible protective effect of anatomical ACL reconstruction.

Conclusion: Osteoarthritis after ACL injury is seen after both operative and non-operative treatment. Therefore, there is still a need for prospective, randomised controlled trials to evaluate the hypothesised preventative effect of anatomical ACL reconstruction on the development of PTOA.

In active patients wishing to return to jumping, cutting and pivoting sports (eg, soccer, football, handball, basketball): Operative treatment is the preferred option to maintain athletic participation in the medium to long term (1 to $5+$ years after injury).

Agree $23 / 23,100 \%$

In active patients wishing to return to pivoting and cutting sports, ACL reconstruction is the preferred treatment option to maintain participation in the medium to long term. However, overall, only $65 \%$ of patients return to their preinjury sports level after ACL reconstruction and only 55\% return to competitive-level sport. ${ }^{80}$ Although the exact reasons are still unknown, younger age, male gender, professional sports level and positive psychological response were demonstrated to be associated with a successful return to preinjury sports level after ACL reconstruction. In general, elite athletes return to their preinjury level of sports after ACL reconstruction more often than recreational athletes. ${ }^{81}{ }^{82}$ For instance, over $90 \%$ of elite soccer players were reported to return to the preinjury level after ACL reconstruction. ${ }^{81}$ Similarly, in a recent systematic review, the return to sport rate in elite football and basketball players was $78 \%$ and $82 \%$, respectively. ${ }^{82}$ In contrast only $12.8 \%$ of high-level athletes returned to the preinjury sports level with non-operative treatment, with a high rate of secondary meniscus and cartilage damage; after 20 years $95 \%$ of the patients underwent meniscectomy, during which $68 \%$ of patients were found to have chondral lesions. ${ }^{2683}$ Overall, athletes returned to their preinjury sports level between 6 months and 13 months after ACL reconstruction. ${ }^{82}$

Conclusion: In active patients anatomical ACL reconstruction is the preferred treatment due to the higher rate of return to the preinjury sports level.
In active patients wishing to return to jumping, cutting and pivoting sports (eg, soccer, football, handball, basketball): Return to cutting and pivoting sports without surgery places the knee at risk of secondary injury (meniscus, cartilage, etc). Agree $23 / 23,100 \%$

In a prospective randomised controlled trial, patients with high activity level (median Tegner Activity Score of 9) with isolated ACL tears received early operative treatment or nonoperative treatment with the option of delayed ACL reconstruction. Although no differences were evident for patient-reported outcomes, at the 2-year follow-up patients in the 'optional' operative treatment group had more self-reported and clinical laxity of the involved knee and more meniscal surgery over a 5-year follow-up period. ${ }^{8}$ In a separate cohort, the risk for sustaining at least one additional intra-articular injury increased by $0.6 \%$ with each month of delay in operative treatment. ${ }^{84}$ The odds of secondary cartilage lesions increased by nearly $1 \%$ for each month of delay. ${ }^{85}$ A delay in ACL reconstruction of at least 12 months almost doubled the risk for meniscal tears. ${ }^{84}{ }^{86}$ Increased risk of secondary injury is especially noted in young ( $<12$ years) and skeletally immature patients. ${ }^{67}$

Conclusion: Non-operative treatment increases the risk for secondary injuries if the patient wants to return to jumping, cutting and pivoting sports, due to the increased risk of further episodes of instability.

In active patients wishing to return to cutting and pivoting sports (eg, soccer, football, handball, basketball):

Delayed operative treatment may be an option for temporary return to athletic participation following non-operative treatment accepting the risk of additional injury.

Agree $10 / 23,43.4 \%$

No consensus was reached for this statement. Some professional athletes and active patients want to delay ACL reconstruction in order to temporarily return to athletic participation (competition). Based on current evidence, the risk of secondary damage to the knee (eg, meniscus, cartilage) is high, especially in high-demand sports with jumping, cutting and pivoting. In a recent cross-sectional study, 860 patients were included with $47.2 \%$ being professional athletes. With regard to prevalence of meniscus tears, medial, lateral and combined lesions were found more often with increasing time from injury (TFI) to surgery (medial meniscus tear prevalence at $0-36$ weeks TFI was $48.2 \%$ and when $>61$ weeks was $59.3 \%$ ). The prevalence of injury increased with time, and the rate of meniscectomy also increased (medial meniscectomy at $0-36$ weeks TFI was $7.5 \%$ and when TFI was $>61$ weeks it was $12.8 \%)^{87}$

Conclusion: Delayed ACL reconstruction in active patients may be a treatment option, but the provider, as well as the patient, must be aware of the risk of secondary injuries with worse long-term outcomes.

In active patients wishing to return to straight plane activities (eg, running, cycling, swimming, weightlifting, etc): Nonoperative treatment is an option.

Agree $23 / 23,100 \%$

Straight plane activities are less demanding on the ligamentous stabilisers of the knee and therefore are amenable to nonoperative treatment. The anteroposterior stability during straight plane activities might be maintained by muscular control, but coronal and rotational stability could not be compensated. ${ }^{88}$ 
With specific neuromuscular training (perturbation training) additional to standard rehabilitation unphysiological muscular co-contractions during walking can be minimised and knee kinematics can be normalised in the ACL deficient knee. ${ }^{15}$ In a matched paired study non-operative treatment resulted in an earlier return (non-operative 3-4 months vs operative 6-12 months) and a higher return to level II sports (non-operative $88.9 \%$ vs operative $77.8 \%$ ) as compared with operative treatment. ${ }^{30}$ Another study demonstrated a significantly higher number of non-operatively treated patients returned to level II and level III sports compared with operative treatment. ${ }^{29}$

Conclusion: For return to straight plane activities nonoperative treatment is an option.

In active patients wishing to return to straight plane activities (eg, running, cycling, swimming, weight-lifting, etc):

In the case of persistent instability in daily life, operative treatment is appropriate for a return to non-rotational activities. Agree $23 / 23,100 \%$

Straight plane activities are less demanding to the ligamentous stabilisers of the knee and are therefore amenable to nonoperative treatment. If during the non-operative treatment, subjective instability persists or episodes of giving way occur, referral for consideration of anatomical ACL reconstruction is recommended. ${ }^{89}$ Moreover, current evidence for the efficacy of non-operative treatment is limited to isolated ACL tears.

Conclusion: Based on current evidence, persistent instability in activities of daily living is an indication for anatomical ACL reconstruction to restore knee laxity and prevent secondary injuries.

\section{CONCLUSION}

The expert panel at the ACL Consensus Meeting Panther Symposium 2019 reached consensus, defined as $>80 \%$ agreement, on 11 of 12 statements in terms of operative versus non-operative treatment for ACL injuries. Consensus was reached that both treatment options may be acceptable, depending on patient characteristics, including the type of sporting demands and the presence of concomitant injuries. In highly active patients engaged in jumping, cutting and pivoting sports, early anatomical ACL reconstruction is recommended due to the high risk of secondary meniscus and cartilage injuries with delayed surgery, although a period of progressive rehabilitation to resolve impairments and improve neuromuscular function may be recommended. For patients who want to return to straight plane activities, nonoperative treatment with structured, progressive rehabilitation is an acceptable treatment option. However, with persistent functional instability, or when episodes of giving way occur, anatomical ACL reconstruction is indicated.

Despite strong consensus by experts, there is a need for larger randomised trials with longer-term follow-up in which early surgery (followed by rehabilitation) is compared with a strategy of early rehabilitation and delayed surgery. There is insufficient data to guide treatment in instances when there are concomitant meniscal and collateral ligament injuries. Data on long-term clinical outcomes are needed to better understand the effect of ACL treatment of injuries, subsequent injuries to meniscus and cartilage, and the development of osteoarthritis.

\section{Author affiliations}

'Department of Sportorthopedics, Klinikum rechts der Isar der Technischen Universitat Munchen, Munchen, Germany
${ }^{2}$ Department of Orthopaedic Surgery, UPMC Freddie Fu Sports Medicine Center, University of Pittsburgh Medical Center, Pittsburgh, Pennsylvania, USA

${ }^{3}$ Division of Orthopedic Surgery, Oslo University Hospital, Oslo, Norway

${ }^{4}$ Department of Physical Therapy, School of Health and Rehabilitation Sciences, University of Pittsburgh, Pittsburgh, Pennsylvania, USA

${ }^{5}$ Institue of Clinical Sciences, Department of Orthopaedics, Goteborgs Universitet, Goteborg, Sweden

${ }^{6}$ Department of Health and Rehabilitation, Institute of Neuroscience and Physiology, Gothenburg, Sweden

${ }^{7}$ Department of Orthopaedic Surgery, UPMC Freddie Fu Sports Medicine Center, University of Pittsburgh, Pittsburgh, Pennsylvania, USA

${ }^{8}$ Department of Orthopaedics, University of Maryland School of Medicine, Baltimore, MD, USA

${ }^{9}$ Department of Trauma Surgery, University Hospital Zurich, Zurich, Switzerland

${ }^{10}$ Division of Orthopaedic Surgery, Department of Surgery, McMaster University,

Hamilton, Ontario, Canada

${ }^{11}$ Division of Sports Medicine, Cincinnati Children's Hospital Medical Center,

Cincinnati, Ohio, USA

${ }^{12}$ Department of Orthopaedics, Emory University School of Medicine, Atlanta,

Georgia, USA

${ }^{13}$ Department of Orthopaedics, Sahlgrenska University Hospital, Mölndal, Sweden

Twitter Lars Engebretsen @larsengebretsen and Eric Andrew Hamrin Senorski @senorski

Collaborators Panther Consensus Group Olufemi R. Ayeni, Charles H. Brown Jr., Terese L. Chmielewski, Mark Clatworthy, Stefano Della Villa, Theresa Diermeier, Lars Engebretsen, Lucio Ernlund, Christian Fink, Freddie H. Fu, Alan Getgood, Timothy E. Hewett, Yasuyuki Ishibashi, Darren L. Johnson, Jon Karlsson, Andrew D. Lynch, Jeffrey A. Macalena, Robert G. Marx, Jacques Menetrey, Sean J. Meredith, Volker Musahl, Kentaro Onishi, Mark V. Paterno, Thomas Rauer, Benjamin B. Rothrauff, Laura C. Schmitt, Romain Seil, Eric H. Senorski, Rainer Siebold, Lynn Snyder-Mackler, Tim Spalding, Eleonore Svantesson, Kevin E. Wilk, John W. Xerogeanes.

Contributors TD, BBR, JK, VM, ES, EAHS, TR and SJM contributed substantially to the conception of the paper and interpretation of data. LE, AL, ORA, MP, JWX and FF contributed substantially towards revising the manuscript critically and final approval of this manuscript.

Funding The authors have not declared a specific grant for this research from any funding agency in the public, commercial or not-for-profit sectors.

Competing interests None declared.

Patient consent for publication Not required.

Provenance and peer review Not commissioned; externally peer reviewed.

Data availability statement All data relevant to the study are included in the article

\section{ORCID iDs}

Theresa Anita Diermeier http://orcid.org/0000-0002-0549-5212

Eleonor Svantesson http://orcid.org/0000-0002-6669-5277

Eric Andrew Hamrin Senorski http://orcid.org/0000-0002-9340-0147

Sean J Meredith http://orcid.org/0000-0003-3725-5309

\section{REFERENCES}

1 Lynch TS, Parker RD, Patel RM, et al. The impact of the multicenter orthopaedic outcomes network (moon) research on anterior cruciate ligament reconstruction and orthopaedic practice. J Am Acad Orthop Surg 2015:23:154-63.

2 Kaeding CC, Léger-St-Jean B, Magnussen RA. Epidemiology and diagnosis of anterior cruciate ligament injuries. Clin Sports Med 2017:36:1-8.

3 Granan L-P, Bahr R, Steindal K, et al. Development of a national cruciate ligament surgery registry: the Norwegian national knee ligament registry. Am J Sports Med 2008;36:308-15.

4 Zantop T, Herbort M, Raschke MJ, et al. The role of the anteromedial and posterolateral bundles of the anterior cruciate ligament in anterior tibial translation and internal rotation. Am J Sports Med 2007;35:223-7.

5 Musahl V, Kopf S, Rabuck S, et al. Rotatory knee laxity tests and the pivot shift as tools for ACL treatment algorithm. Knee Surg Sports Traumatol Arthrosc 2012;20:793-800.

6 Boden BP, Dean GS, Feagin JA, et al. Mechanisms of anterior cruciate ligament injury. Orthopedics 2000;23:573-8

7 Alentorn-Geli E, Myer GD, Silvers HJ, et al. Prevention of non-contact anterior cruciate ligament injuries in soccer players. Part 1: mechanisms of injury and underlying risk factors. Knee Surg Sports Traumatol Arthrosc 2009;17:705-29.

8 Frobell RB, Roos EM, Roos HP, et al. A randomized trial of treatment for acute anterior cruciate ligament tears. N Engl J Med 2010;363:331-42.

9 Frobell RB, Roos HP, Roos EM, et al. Treatment for acute anterior cruciate ligament tear: five year outcome of randomised trial. BMJ 2013;346:f232. 
10 Hurd WJ, Axe MJ, Snyder-Mackler L. A 10-year prospective trial of a patient management algorithm and screening examination for highly active individuals with anterior cruciate ligament injury: Part 2, determinants of dynamic knee stability. Am $J$ Sports Med 2008;36:48-56.

11 Stannard JP, Brown SL, Farris RC, et al. The posterolateral corner of the knee: repair versus reconstruction. Am J Sports Med 2005:33:881-8.

$12 \mathrm{Fu} \mathrm{FH}$, van Eck CF, Tashman S, et al. Anatomic anterior cruciate ligament reconstruction: a changing paradigm. Knee Surg Sports Traumatol Arthrosc 2015;23:640-8

13 Eitzen I, Moksnes H, Snyder-Mackler L, et al. A progressive 5-week exercise therapy program leads to significant improvement in knee function early after anterior cruciate ligament injury. J Orthop Sports Phys Ther 2010;40:705-21.

14 Paterno MV. Non-Operative care of the patient with an ACL-Deficient knee. Curr Rev Musculoskelet Med 2017:10:322-7.

15 Chmielewski TL, Hurd WJ, Rudolph KS, et al. Perturbation training improves knee kinematics and reduces muscle co-contraction after complete unilateral anterior cruciate ligament rupture. Phys Ther 2005;85:740-9.

16 Fitzgerald GK, Axe MJ, Snyder-Mackler L. The efficacy of perturbation training in nonoperative anterior cruciate ligament rehabilitation programs for physical active individuals. Phys Ther 2000;80:128-40.

17 Ardern CL, Österberg A, Tagesson S, et al. The impact of psychological readiness to return to sport and recreational activities after anterior cruciate ligament reconstruction. Br J Sports Med 2014:48:1613-9.

18 van Eck CF, Lesniak BP, Schreiber VM, et al. Anatomic single- and double-bundle anterior cruciate ligament reconstruction flowchart. Arthroscopy 2010;26:258-68.

19 Pauzenberger L, Syré S, Schurz M. "Ligamentization" in hamstring tendon grafts after anterior cruciate ligament reconstruction: a systematic review of the literature and a glimpse into the future. Arthroscopy 2013;29:1712-21.

20 Scheffler SU, Unterhauser FN, Weiler A. Graft remodeling and ligamentization after cruciate ligament reconstruction. Knee Surg Sports Traumatol Arthrosc 2008; 16:834-42

21 van Yperen DT, Reijman M, van Es EM, et al. Twenty-Year follow-up study comparing operative versus Nonoperative treatment of anterior cruciate ligament ruptures in high-level athletes. Am I Sports Med 2018;46:1129-36.

22 Neuman P, Englund M, Kostogiannis I, et al. Prevalence of Tibiofemoral osteoarthritis 15 years after Nonoperative treatment of anterior cruciate ligament injury. $\mathrm{Am} J$ Sports Med 2008;36:1717-25.

23 Hangalur G, Brenneman E, Nicholls M, et al. Can a knee brace reduce the strain in the anterior cruciate ligament? A study using combined in vivo/in vitro method. Prosthet Orthot Int 2016;40:394-9.

24 Sitler M, Ryan J, Hopkinson W, et al. The efficacy of a prophylactic knee brace to reduce knee injuries in football. A prospective, randomized study at West point. Am 」 Sports Med 1990;18:310-5.

25 Noyes FR, Matthews DS, Mooar PA, et al. The symptomatic anterior cruciate-deficient knee. Part II: the results of rehabilitation, activity modification, and counseling on functional disability. J Bone Joint Surg Am 1983:65:163-74.

26 Fitzgerald GK, Axe MJ, Snyder-Mackler L. A decision-making scheme for returning patients to high-level activity with nonoperative treatment after anterior cruciate ligament rupture. Knee Surg Sports Traumatol Arthrosc 2000;8:76-82.

27 Noyes FR, Barber SD, Mangine RE. Abnormal lower limb symmetry determined by function hop tests after anterior cruciate ligament rupture. Am I Sports Med 1991:19:513-8

28 Charles C, Gafni A, Whelan T. Shared decision-making in the medical encounter: what does it mean? (or it takes at least two to tango). Soc Sci Med 1997:44:681-92.

29 Grindem H, Eitzen I, Engebretsen L, et al. Nonsurgical or surgical treatment of ACL injuries: knee function, sports participation, and knee Reinjury: the Delaware-Oslo ACL cohort study. J Bone Joint Surg Am 2014;96:1233-41.

30 Grindem H, Eitzen I, Moksnes H, et al. A pair-matched comparison of return to pivoting sports at 1 year in anterior cruciate ligament-injured patients after a nonoperative versus an operative treatment course. Am J Sports Med 2012;40:2509-16

31 Thoma LM, Grindem H, Logerstedt D, et al. Coper classification early after anterior cruciate ligament rupture changes with progressive neuromuscular and strength training and is associated with 2-year success: the Delaware-Oslo ACL cohort study. Am J Sports Med 2019;47:807-14.

32 Kvist J, Kartus J, Karlsson J, et al. Results from the Swedish national anterior cruciate ligament register. Arthroscopy 2014;30:803-10.

33 Nippert AH, Smith AM. Psychologic stress related to injury and impact on sport performance. Phys Med Rehabil Clin N Am 2008;19:399-418.

34 Flint FA, Weiss MR. Returning injured athletes to competition: a role and ethical dilemma. Can J Sport Sci 1992;17:34-40

35 Ineke V, John MH. Coaches' Decision Policies about the Participation of Injured Athletes in Competition. The Sport Psychologist 1999;13:42-56.

36 Cimino PM. The incidence of meniscal tears associated with acute anterior cruciate ligament disruption secondary to snow skiing accidents. Arthroscopy 1994;10:198-200
37 Borchers JR, Kaeding CC, Pedroza AD, et al. Intra-Articular findings in primary and revision anterior cruciate ligament reconstruction surgery: a comparison of the moon and MARS study groups. Am J Sports Med 2011;39:1889-93.

38 Sarraj M, Coughlin RP, Solow M, et al. Anterior cruciate ligament reconstruction with concomitant meniscal surgery: a systematic review and meta-analysis of outcomes. Knee Surg Sports Traumatol Arthrosc 2019:27:3441-52.

39 Phillips M, Rönnblad E, Lopez-Rengstig L, et al. Meniscus repair with simultaneous $\mathrm{ACL}$ reconstruction demonstrated similar clinical outcomes as isolated $\mathrm{ACL}$ repair: a result not seen with meniscus resection. Knee Surg Sports Traumatol Arthrosc 2018;26:2270-7.

40 Lorbach O, Kieb M, Domnick C, et al. Biomechanical evaluation of knee kinematics after anatomic single- and anatomic double-bundle $\mathrm{ACL}$ reconstructions with medial meniscal repair. Knee Surg Sports Traumatol Arthrosc 2015;23:2734-41.

41 Zaffagnini S, Signorelli C, Grassi A, et al. Anatomic anterior cruciate ligament reconstruction using hamstring tendons restores quantitative pivot shift. Orthop Sports Med 2018;6:232596711881236

42 Cohen M, Amaro JT, Ejnisman B, et al. Anterior cruciate ligament reconstruction after 10 to 15 years: association between meniscectomy and osteoarthrosis. Arthroscopy 2007:23:629-34.

43 Magnussen RA, Mansour AA, Carey JL, et al. Meniscus status at anterior cruciate ligament reconstruction associated with radiographic signs of osteoarthritis at 5- to 10-year follow-up: a systematic review. J Knee Surg 2009;22:347-57.

44 Wu WH, Hackett T, Richmond JC. Effects of meniscal and articular surface status on knee stability, function, and symptoms after anterior cruciate ligament reconstruction: a long-term prospective study. Am J Sports Med 2002;30:845-50.

45 Musahl V, Citak M, O'Loughlin PF, et al. The effect of medial versus lateral meniscectomy on the stability of the anterior cruciate ligament-deficient knee. Am J Sports Med 2010;38:1591-7.

46 Hertel P, Behrend H, Cierpinski T, et al. Acl reconstruction using bone-patellar tendonbone press-fit fixation: 10-year clinical results. Knee Surg Sports Traumatol Arthrosc 2005; 13:248-55.

47 Krutsch W, Zellner J, Baumann F, et al. Timing of anterior cruciate ligament reconstruction within the first year after trauma and its influence on treatment of cartilage and meniscus pathology. Knee Surg Sports Traumatol Arthrosc 2017:25:418-25.

48 Peskun CJ, Whelan DB. Outcomes of operative and nonoperative treatment of multiligament knee injuries: an evidence-based review. Sports Med Arthrosc Rev 2011;19:167-73

49 Levy BA, Dajani KA, Whelan DB, et al. Decision making in the Multiligament-Injured knee: an evidence-based systematic review. Arthroscopy 2009;25:430-8.

50 Richter M, Bosch U, Wippermann B, et al. Comparison of surgical repair or reconstruction of the cruciate ligaments versus nonsurgical treatment in patients with traumatic knee dislocations. Am I Sports Med 2002:30:718-27.

51 Levy BA, Dajani KA, Morgan JA, et al. Repair versus reconstruction of the fibular collateral ligament and posterolateral corner in the multiligament-injured knee. Am J Sports Med 2010;38:804-9.

52 Rahnemai-Azar AA, Abebe ES, Johnson P, et al. Increased lateral tibial slope predicts high-grade rotatory knee laxity pre-operatively in ACL reconstruction. Knee Surg Sports Traumatol Arthrosc 2017;25:1170-6.

53 Voos JE, Suero EM, Citak M, et al. Effect of tibial slope on the stability of the anterior cruciate ligament-deficient knee. Knee Surg Sports Traumatol Arthrosc 2012;20:1626-31.

54 Pfeiffer TR, Burnham JM, Hughes JD, et al. An increased lateral femoral condyle ratio is a risk factor for anterior cruciate ligament injury. J Bone Joint Surg Am 2018:100:857-64.

55 Pfeiffer TR, Burnham JM, Kanakamedala AC, et al. Distal femur morphology affects rotatory knee instability in patients with anterior cruciate ligament ruptures. Knee Surg Sports Traumatol Arthrosc 2019;27:1514-9.

56 Noyes FR, Schipplein OD, Andriacchi TP, et al. The anterior cruciate ligament-deficient knee with varus alignment. An analysis of gait adaptations and dynamic joint loadings. Am J Sports Med 1992;20:707-16.

57 van de Pol GJ, Arnold MP, Verdonschot N, et al. Varus alignment leads to increased forces in the anterior cruciate ligament. Am I Sports Med 2009:37:481-7.

58 Musahl V, Rahnemai-Azar AA, Costello J, et al. The influence of meniscal and anterolateral capsular injury on knee laxity in patients with anterior cruciate ligament injuries. Am J Sports Med 2016:44:3126-31.

59 Hoshino Y, Miyaji N, Nishida K, et al. The concomitant lateral meniscus injury increased the pivot shift in the anterior cruciate ligament-injured knee. Knee Surg Sports Traumatol Arthrosc 2019;27:646-651

60 Sundemo D, Blom A, Hoshino Y, et al. Correlation between quantitative pivot shift and generalized joint laxity: a prospective multicenter study of ACL ruptures. Knee Surg Sports Traumatol Arthrosc 2018;26:2362-70

61 Chmielewski TL, Stackhouse S, Axe MJ, et al. A prospective analysis of incidence and severity of quadriceps inhibition in a consecutive sample of 100 patients with complete acute anterior cruciate ligament rupture. J Orthop Res 2004;22:925-30.

62 Lynch AD, Logerstedt DS, Axe MJ, et al. Quadriceps activation failure after anterior cruciate ligament rupture is not mediated by knee joint effusion. J Orthop Sports Phys Ther 2012;42:502-10. 
63 Palmieri-Smith RM, Kreinbrink J, Ashton-Miller JA, et al. Quadriceps inhibition induced by an experimental knee joint effusion affects knee joint mechanics during a singlelegged drop landing. Am J Sports Med 2007;35:1269-75.

64 Failla MJ, Logerstedt DS, Grindem H, et al. Does extended preoperative rehabilitation influence outcomes 2 years after $\mathrm{ACL}$ reconstruction? A comparative effectiveness study between the moon and Delaware-Oslo ACL cohorts. Am J Sports Med 2016;44:2608-14

65 Jonsson H, Riklund-Ahlström K, Lind J. Positive pivot shift after ACL reconstruction predicts later osteoarthrosis: 63 patients followed 5-9 years after surgery. Acta Orthop Scand 2004;75:594-9.

66 Sommerfeldt M, Raheem A, Whittaker J, et al. Recurrent instability episodes and meniscal or cartilage damage after anterior cruciate ligament injury: a systematic review. Orthop J Sports Med 2018;6:232596711878650.

67 Anderson AF, Anderson CN. Correlation of meniscal and articular cartilage injuries in children and adolescents with timing of anterior cruciate ligament reconstruction. Am J Sports Med 2015;43:275-81.

68 Kluczynski MA, Marzo JM, Bisson LJ. Factors associated with meniscal tears and chondral lesions in patients undergoing anterior cruciate ligament reconstruction: a prospective study. Am J Sports Med 2013:41:2759-65.

69 Fairbank TJ. Knee joint changes after meniscectomy. J Bone Joint Surg Br 1948;30B:664-70.

70 Keays SL, Newcombe PA, Bullock-Saxton JE, et al. Factors involved in the development of osteoarthritis after anterior cruciate ligament surgery. Am J Sports Med 2010;38:455-63.

71 Fayard J-M, Sonnery-Cottet B, Vrgoc G, et al. Incidence and risk factors for a partial anterior cruciate ligament tear progressing to a complete tear after Nonoperative treatment in patients younger than 30 years. Orthop J Sports Med 2019:7:232596711985662

72 Glyn-Jones S, Palmer AJR, Agricola R, et al. Osteoarthritis. Lancet 2015;386:376-87.

73 Vincent TL. Targeting mechanotransduction pathways in osteoarthritis: a focus on the pericellular matrix. Curr Opin Pharmacol 2013;13:449-54.

74 Troeberg L, Nagase H. Proteases involved in cartilage matrix degradation in osteoarthritis. Biochim Biophys Acta 2012;1824:133-45.

75 Muthuri SG, McWilliams DF, Doherty M, et al. History of knee injuries and knee osteoarthritis: a meta-analysis of observational studies. Osteoarthritis Cartilage 2011;19:1286-93.

76 Meuffels DE, Favejee MM, Vissers MM, et al. Ten year follow-up study comparing conservative versus operative treatment of anterior cruciate ligament ruptures. A matched-pair analysis of high level athletes. Br J Sports Med 2009;43:347-51.

77 Sanders TL, Kremers HM, Bryan AJ, et al. Is anterior cruciate ligament reconstruction effective in preventing secondary meniscal tears and osteoarthritis? Am J Sports Med 2016:44:1699-707.
78 Fithian DC, Paxton EW, Stone ML, et al. Prospective trial of a treatment algorithm for the management of the anterior cruciate ligament-injured knee. Am J Sports Med 2005;33:335-46

79 Lie MM, Risberg MA, Storheim K, et al. What's the rate of knee osteoarthritis 10 years after anterior cruciate ligament injury? an updated systematic review. $\mathrm{Br}$ J Sports Med 2019;53:1162-7.

80 Ardern CL, Taylor NF, Feller JA, et al. Fifty-five per cent return to competitive sport following anterior cruciate ligament reconstruction surgery: an updated systematic review and meta-analysis including aspects of physical functioning and contextual factors. Br J Sports Med 2014;48:1543-52.

81 Waldén $M$, Hägglund $M$, Magnusson $\mathrm{H}$, et al. Anterior cruciate ligament injury in elite football: a prospective three-cohort study. Knee Surg Sports Traumatol Arthrosc 2011;19:11-19.

82 Lai CCH, Ardern CL, Feller JA, et al. Eighty-three per cent of elite athletes return to preinjury sport after anterior cruciate ligament reconstruction: a systematic review with meta-analysis of return to sport rates, graft rupture rates and performance outcomes. Br J Sports Med 2018:52:128.

83 Nebelung $W$, Wuschech $\mathrm{H}$. Thirty-Five years of follow-up of anterior cruciate ligamentdeficient knees in high-level athletes. Arthroscopy 2005;21:696-702.

84 Brambilla L, Pulici L, Carimati G, et al. Prevalence of associated lesions in anterior cruciate ligament reconstruction: correlation with surgical timing and with patient age, sex, and body mass index. Am J Sports Med 2015;43:2966-73.

85 Granan L-P, Bahr R, Lie SA, et al. Timing of anterior cruciate ligament reconstructive surgery and risk of cartilage lesions and meniscal tears: a cohort study based on the Norwegian national knee ligament registry. Am J Sports Med 2009;37:955-61.

86 Lawrence JTR, Argawal N, Ganley TJ. Degeneration of the knee joint in skeletally immature patients with a diagnosis of an anterior cruciate ligament tear: is there harm in delay of treatment? Am J Sports Med 2011;39:2582-7.

87 Sommerfeldt M, Goodine T, Raheem A, et al. Relationship between time to $\mathrm{ACL}$ reconstruction and presence of adverse changes in the knee at the time of reconstruction. Orthop J Sports Med 2018;6:232596711881391.

88 Waite JC, Beard DJ, Dodd CAF, et al. In vivo kinematics of the ACL-deficient limb during running and cutting. Knee Surg Sports Traumatol Arthrosc 2005:13:377-84.

89 Meunier A, Odensten M, Good L. Long-Term results after primary repair or nonsurgical treatment of anterior cruciate ligament rupture: a randomized study with a 15-year follow-up. Scand J Med Sci Sports 2007;17:061120070736040-???

90 van Eck CF, Gravare-Silbernagel K, Samuelsson K, et al. Evidence to support the interpretation and use of the anatomic anterior cruciate ligament reconstruction checklist. J Bone Joint Surg Am 2013;95:e153. 